\title{
THE WOMEN, OF COURSE
}

\section{Becky Soglin}

There's a family photograph I first saw several years ago that always made me wonder, "Where's Uncle Sol?" But I'd never asked my mother why he isn't in the picture. Looking at it one day, it dawned on me, finally, that he may have taken it. Although it's an informal shot, it seems he should have been in the photo, to make complete his and my mother's own family, and let one of my grandfather's two nephews, who do appear, take it instead.

It's an outdoor scene, and I thought it was probably taken on a weekend outing to Grant Park in Chicago. The left side of the photo is overexposed, but the right side is nearly distinct enough to make out the ridges of the bark on a tree, the thin metal rims of the wheels on a cart, and in the distance two or three figures grouped near a pole.

Six of my relations are in the photo, and they manage to form a diamond shape, which, as in a dramatic painting like the one in the Louvre of the raft piled with shipwrecked survivors, draws your attention to a certain point: my mother, Rose. She is a child, two or so, the point at the bottom, center of the photo. She is flanked on one side by her older sister, Frieda, and their mother, Esther. To her other side, Chaim, her father, and Chaim Hersh Greenband, one of the nephews, whose names are written on the back of the photo. Chaim Hersh's brother, Sam, completes the shape by kneeling behind everyone, such that his head forms the top point of the diamond.

My mother's shock of black hair is as black as her eyes. Her mouth is tiny, and somewhere between forming the shape of a scowl and a cry. Looking at that face, I could only think: this must have been the moment she found out she was a mistake. That explained why Esther and Frieda are looking down. My grandmother must have been the one who revealed the fact, then felt bad. Esther was not a cruel woman. I'd always known this from my own mother, and not just from the two things I remembered about Grandma Century: how she'd bake blueberry muffins for us and how, when she became senile, she'd kiss my brothers and me on our foreheads, smooth back our hair and call all three of us 
shane madeles - pretty girls. No, she was not cruel. I imagined: it's just that it was 1925, times were hard even though it wasn't yet the Depression, and she was well into her forties with this toddler to take care of. And the fact probably came out because my mother made a fuss about sitting, not standing, for the picture. Frieda surely wanted to make things better, as always for her sister ten years younger; her lips are parted as if she wants to say something.

My grandfather stares directly into the camera. He looks business-like, wearing a striped tie and holding a cigar in his left hand. I never met him but the few photos I'd seen of him suggest this was not how he really looked. The typical photo from the summer stays in the Indiana dunes shows him strolling on the sand, wearing only white shorts, looking remarkably like Gandhi. And, I'd been told, he had many of Gandhi's qualities - he was a gentle, gentle man, a woodcarver who could transform a peach pit into a miniature vase or a butterfly. I concluded that the fact revealed by my grandmother had taken him off guard, not that he hadn't known it, but how could she have said it?; he was merely trying to remain composed for the picture.

Chaim Hersh sits in the exact pose as my grandfather, except his tie is askew and he isn't holding a cigar. I didn't know much about this Chaim, except that he was surely named after my grandfather. (The family used the same names so often that at one time there were three Rose Centurys and three Frieda Centurys, all of them in Chicago, among them my mother and my aunt.) The other nephew, Sam, is looking off to his right-this Sunday outing probably wasn't his idea of how to spend the day, and then, little Rosie was told she was a mistake.

Of course, as my friend pointed out after I showed her the photo, it's quite possible my mother was scowling because she didn't like her haircut.

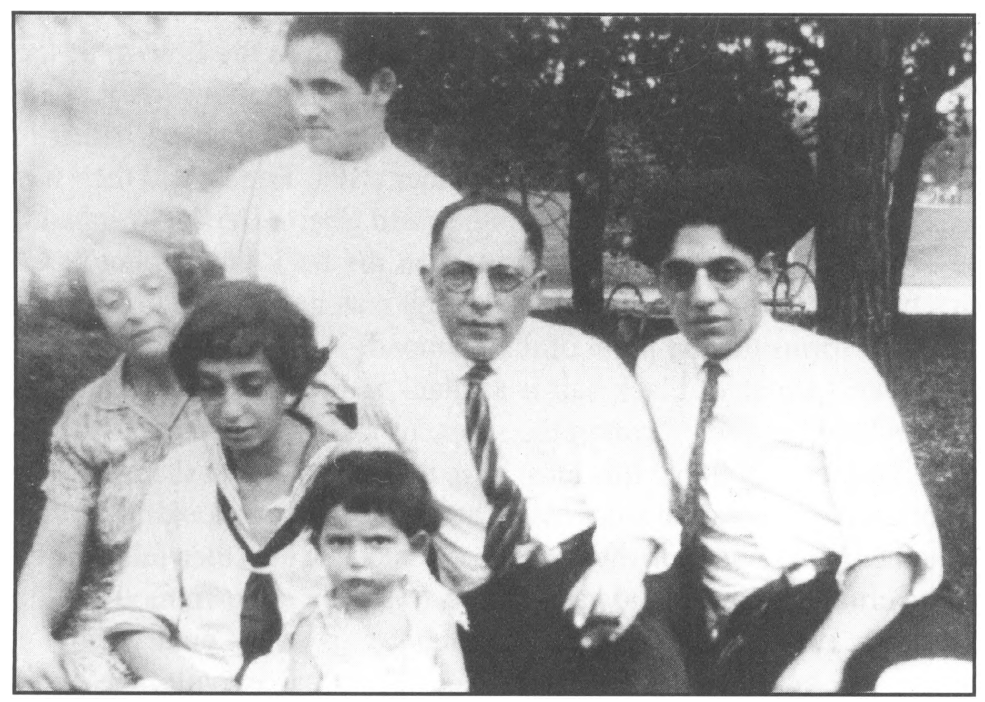


I propped the photograph against the lamp by the phone and called my mother to ask her about it. Mainly I wanted to know whether she was three-years-old, or only two when it was taken. I don't know why that seemed so important to me. Maybe it was because of that look on her face, for which I had extrapolated an explanation, and so I wanted a fact that was easy to grasp. She knew immediately which photo I was talking about and said she thought she was three. I told her what I had imagined about the photo, that it captured the moment she learned the truth of her conception. And as I spoke, I worried she thought I saw her mother as cruel, despite my own rejection of that thought. She interrupted me only once, to say that Frieda is eleven, not ten, years older than she is. When I told her what my friend had said about her haircut, she laughed.

Then she said the photo was probably taken at the Magnus's farm in Michigan. They were family friends-Mr. Magnus had been a pharmacist in Chicago and decided to become a farmer. They took in summer boarders, and my mother and her family occasionally went to the farm for a week's stay in the summer. Sol isn't in the picture because he "was seventeen and didn't hang out with his family anymore." It was because of Mrs. Magnus, Minnie Magnus, my mother said, that she learned she was a mistake. Then, incredibly: "It may have been on that very visit to the farm." Could it have been?

She explained, "We were in the kitchen and Mrs. Magnus—-she was always 'Mrs. Magnus' - asked Grandma wasn't she glad she had me even though she hadn't wanted me." My mother wondered if that was the right wording: maybe it was "hadn't planned" her. She and I had talked on other occasions about her knowing she was a mistake. But what she said next surprised me, even though I later remembered it was something she had told me at least once before: between Frieda's birth and her own, her mother had several abortions. Images of sisters and brothers my mother never had; phantom aunts and uncles to me. I asked why so many. My mother said maybe it was just one abortion. Esther took precautions - she knew about birth control—but "things failed," and she and grandpa couldn't afford to have more children. "It was hard enough already." It didn't seem like the kind of question to ask one's mother, but I asked mine why grandma hadn't had an abortion when she was pregnant with her. "She waited too long. She thought she was going through early menopause."

I asked my mother again about when she first learned she was a mistake, if it really could have been during the visit captured in this picture. It turned out it was my comment about the cart that made her think it was the farm. I told her I thought it was a cart but couldn't be sure. And I told her the setting just didn't look like a farm. "The flat field behind you isn't planted with anything, and it looks as if there's a paved pathway there, too," I said.

"Well, it couldn't have been Grant Park-we wouldn't have gone downtown," she said. "It's probably Garfield Park or Humboldt Park. Grandpa liked to go to Garfield Park to see the tulip garden. He loved such things." And she reminded me I did meet him, rather he met me-I was three months old when he died. And suddenly I felt tiny enough to be cradled in someone's arms. How could I have forgotten he was alive when I was born? 
And what about Chaim Hersh, the nephew resembling grandpa in more than name? He was cousin Lorraine's father, my mother explained. "You met him a few times when he was in his 80s." I could picture cousin Lorraine-plump, with curly reddish hair and a pleasant laugh—but I couldn't picture him, despite my mother's description. "He and Sam were Pearl and Frieda's brothers," she said. Pearl and Frieda, I remembered them-they lived well into their eighties and would often call to talk to my mother, always asking me when I answered the phone, "Do you know who this?" And before I could answer, they would say, "Ach, you don't know, do you? So, I'll tell you. . .."

And Sam, who's looking off in the distance? They called him Shmiel, and he died of a kidney disease when he was in his thirties. He had two children and a wife, who was also sickly, so during his illness he sometimes stayed with my grandparents. My mother said she remembers sitting by his bed in the living room, playing for hours on the floor. She loved to be near him. "He was so handsome. Sometimes he would sing. Such a sweet man. Like grandpa," she said. I felt so guilty - for having supposed that Sam didn't want to be on that outing or be part of the photo - and as I thought about that, my mother laughed and said, "The men in the family were a lot sweeter than the women." And I ached a little: could it still be true?

I was thinking not of my own mother or any of the other women in my family, but of myself. And more than any recent rude moment or careless remark for which I was responsible, it was something from my own childhood that came to mind. When we were young, it was my twin brother who always welcomed being held and cuddled, while I would sometimes squirm away. Once, as my father bent to kiss me on the nape of my neck, I lifted my head suddenly, painfully smashing his glasses into his face. I saw the tears in his eyes, but could not explain that I hadn't meant to hurt him. It had disturbed my mother, too. At the time, she was the one who asked me if I realized what I had done. My mother and I talked some more about how old she appears in the photo. I described how small she looks, the baby-plumpness of her arms, the little dress tied at the shoulder with bows - the things that made me wonder if she was only two. "No," she explained, "I was plump until I was six, and then I got skinny and ugly. They'd say to me, 'You used to be so pretty.'" She laughed and added, "The women, of course." 